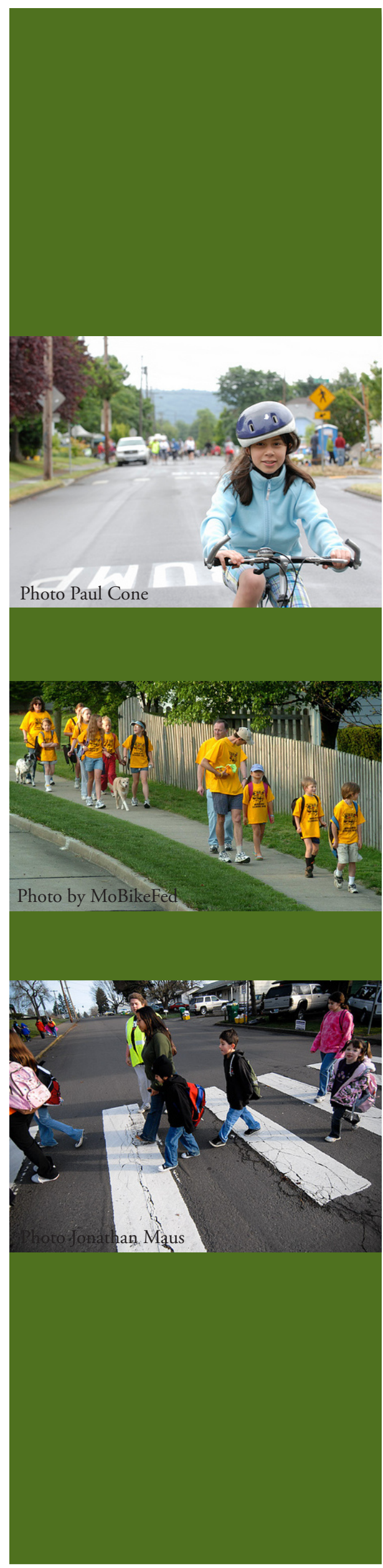

\title{
A Review of Literature:
}

The Effectiveness of Safe Routes to School and Other Programs to Promote Active Transportation to School

\section{Lynn Weigand, Ph.D.}

Portland State University

- Center for Urban Studies

- " Center for Transportation Studies

- " - Initiative for Bicycle and Pedestrian Innovation

June 2008

CUS-CTS-08-01 


\title{
A Review of Literature:
}

\section{The Effectiveness of Safe Routes to School and Other Programs to Promote Active Transportation to School}

\author{
Lynn Weigand, Ph.D. \\ Initiative for Bicycle and Pedestrian Innovation \\ Center for Transportation Studies \\ Center for Urban Studies \\ Portland State University, Portland, Oregon
}

June 2008

CUS-CTS-08-01

\section{Acknowledgements}

This project was funded by the Oregon Transportation Research and Education Consortium (OTREC).

The contents of this report reflect the views of the authors, who are solely responsible for the facts and the accuracy of the material and information presented herein. This document is disseminated under the sponsorship of the U.S. Department of Transportation University Transportation Centers Program and OTREC in the interest of information exchange. The U.S. Government and OTREC assume no liability for the contents or use thereof. The contents do not necessarily reflect the official views of the U.S. Government orOTREC.

The author wishes to thank the following individuals for their review and comment on earlier drafts of this publicaton: Jennifer, Dill, Ph.D., Associate Professor, Nohad A. Toulan School of Urban Studies and Planning, Portland State University; Noreen McDonald, Ph.D., Assistant Professor, Department of City and Regional Planning, University of North Carolina at Chapel Hill; and Marc Schlossberg, Associate Professor, Interim Department Head \& Director of the Undergraduate Program, Department of Planning, Public Policy and Management, University of Oregon.

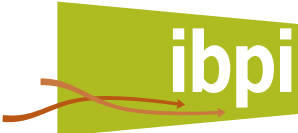

Initiative for Bicycle \& Pedestrian Innovation

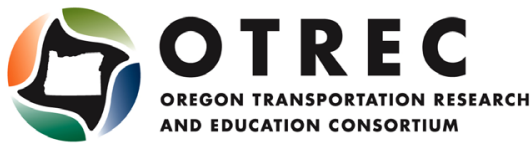

Initiative for Bicycle and Pedestrian Innovation Center for Transportation Studies, Portland State University PO Box 751, Portland, OR 97207-0751

ibpi@pdx.edu

http://ibpi.usp.pdx.edu 


\section{INTRODUCTION}

Programs to promote active transportation to school have been gaining popularity as a way to incorporate physical activity into children's lives, reduce traffic congestion in school zones and improve air quality in communities by eliminating auto trips. While these programs are increasing in numbers and funding, little is known about the outcomes, specifically in terms of travel behavior changes and safety improvements. This paper reviews research that has evaluated programs to increase active transportation to school, focusing on evidence-based studies designed to measure changes in attitudes and behavior about journey to school transportation. It is intended to summarize the state of the knowledge in the field today, identify the gaps in research, and provide direction for future study on this topic.

\section{BACKGROUND}

The number of children who walk or bike to school in the U.S. has decreased dramatically, from 50\% in 1969 to only 15\% in 2001 (Safe Routes to School National Partnership \& Hubsmith, 2007) as more parents drive their children to school. Driving children to school can deprive them of an opportunity for daily physical activity while generating between 20 to 30 percent of morning traffic in some places (Safe Routes to School National Partnership \& Hubsmith, 2007). Around the country, parents, educators and community leaders have become concerned about the implications of this trend for the health and safety of their children but until recently, few programs in the U.S. existed to address this issue.

In other countries, programs to promote safer walking and cycling to school were started more than 30 years ago. Most of these early efforts focused on addressing dangerous situations for children walking or cycling to school and less on promoting these modes of travel. In the 1970s, the City of Odense in Denmark launched one of the first official programs related to walking and cycling to school. Their program was aimed at reducing the high rate of child pedestrian accidents by identifying and addressing road dangers through interventions such new pedestrian and bicycle paths, traffic islands and narrowed roads (Appleyard, 2003). This was followed by programs in Great Britain in the 1980s and 1990s that also focused on reducing hazardous situations. Through new facilities and design, such as bike lanes, traffic calming and raised crossings to increase safety for children traveling to school (Appleyard, 2003). At the same time, programs in New Zealand, Australia and Canada were moving the model forward. Their programs addressed the physical dangers of walking and cycling, and also incorporated more education, encouragement and enforcement elements to increase the number of children who walked or biked to school (Hubsmith, 2006).

In the U.S., programs in New York and Florida were launched in the late 1990s, again focusing primarily on making streets safer for children. In 1997, Chicago initiated the first U.S. Walk to School Day, marking one of the first large-scale efforts to raise awareness and promote behavior change in school travel patterns (Hubsmith, 2006). In 2000, the National Highway Traffic Safety Administration (NHTSA) provided $\$ 50,000$ to two communities - Marin County, California and Boston, Massachusetts - to develop multi-faceted programs aimed at increasing the number of children walking and cycling to school. The Marin County program showed increases in walking and cycling to schools in the first year (Staunton, Hubsmith, \& Kallins, 2003) and led to the establishment of a national Safe Routes to School model program and toolkit. In 2005, the federal surface transportation bill, SAFETEA-LU, allocated \$612 million in funding for Safe Routes to School nationwide. The funding is apportioned to each state for use between 2005 and 2009. The funding mandates that $70-90 \%$ of funds be used for construction projects to increase walking and cycling safety to school, and $10-30 \%$ of the funds be spent on education, encouragement and enforcement programs to improved safety for kids on foot and bike.

Many communities are now actively seeking ways to increase the number of children who can walk or bike safely to school through a variety of programs initiated several fronts, including parents, educators, local government and public health officials, environmental advocates, transportation planners, and law enforcement. These include on-going comprehensive programs, single program activities, such as a walking school bus program, one-time events, such participating 
in the national walk to school day, or physical improvements such as installing more bike parking. Often these communities use the Safe Routes to School moniker for their program, even if they are not following the national model or receiving federal money for their initiatives. Hence, the term Safe Routes to School has come to be a catch-all phrase for any effort to promote safe walking and cycling to school. The following section describes the model Safe Routes to School program, a comprehensive program designed to "to create safe, convenient and fun opportunities for children to walk and bicycle to school." (Hubsmith, 2007).

\section{The Safe Routes to School Program}

The model Safe Routes to School program works at the community level in five areas -- evaluation, education, encouragement, engineering and enforcement - to address health, safety and traffic concerns that include:

- increasing safe, convenient physical activity for children;

- decreasing traffic congestion; and

- improving air quality for communities (Hubsmith, 2007).

Safe Routes to School has become institutionalized at the national level through the funding from the Federal Highway Administration (FHA). State Departments of Transportation (DO'Ts) receive the federal funds and make grants to state, local and regional agencies to implement Safe Routes to School, or SR2S, programs.

Early programs, such as California's, had a strong emphasis on engineering by providing construction funding for pedestrian safety projects or traffic calming projects near schools, while other cities and states invested in programs to educate children, parents and communities about walking and cycling safety, and encouraging nonmotorized transportation to school and enforce traffic laws around schools. (McMillan, 2005):

To date, work and funding at the national level has focused on establishing state programs, which in turn fund local activities and projects. A 2007 report on the status of the national program focuses primarily on organizational accomplishments, such as hiring state coordinators, establishing advisory committees, establishing grant application guidelines and selecting projects. Some data is available on the types and goals of programs, number of students served, and a few have been able to chart changes in travel mode to and from school. It appears that little has been done to measure the effectiveness of the projects and activities at the local level, mostly because few programs have been fully implemented and evaluation is still in the early stages (McGlynn, 2007).

\section{METHODS}

This paper is intended to review the literature evaluating the effectiveness of programs aimed at increasing active transportation to school. With the help of graduate research assistants, we conducted a data base search that included Transportation Libraries Catalog (TLCat), EBSCO Host (Academic Search Premier), Medline, ERIC, Education Full-Text, Urban Studies and Planning, SpringerLink and TRIS online. Key word searches were conducted on each data base for the following words and phrases: safe routes to school, routes to school, safe routes, schools, schools and transportation, walk to school, walking to school, bike to school, biking to school, bicycling to school, journey to school, kids walk to school, physical education for children, physical fitness for children, student's health, travel to school, traveling to school, trip to school, exercise and children, children and walking, children and bicycling, children and cycling, children and biking, healthy children, transportation to school, children and transportation, child transportation, active commuting, active transportation to school, active transport, walking school bus. Additional resources were located from the reference lists and bibliographies that were identified in the database search.

Most of the literature on active transportation to school in the U.S. is written for practitioners and advocates and tends to be primarily descriptive information about the programs following the Safe Routes to School national model. A small subset of this literature reports findings of research evaluating the effectiveness of the program implementation. Most of this work focuses on the changes of safety or travel behavior before and after construction projects near school sites and is the primary focus of this review. 
We also found two other related areas in the literature search: influences on journey-to-school transportation decisions and impacts of active transportation on children's physical activity levels and overall health. Walking and cycling to school can provide an opportunity for children to be active during the day and promote a healthy lifestyle (McKenzie \& Kahan, 2008). Studies such as (A. R. Cooper, Page, Foster, \& Qahwaji, 2003); (A. Cooper et al., 2006); and (Rosenburg, Sallis, Conway, Cain, \& McKenzie, 2006) assessed the physical activity patterns of children by mode of travel to school to determine if children who walk and bike to school are more active than those who travel by car overall. Since this paper is concerned with evaluating the effectiveness of programs that promote active transportation to school rather than evaluating the impact on physical activity levels and health, studies focusing on the activity and health outcomes are not included here. Influences on journey-to-school transportation decisions are discussed in the next section.

\section{INFLUENCES ON J OURNEY-TO- SCHOOL TRANSPORTATION DECISIONS}

\section{Overview}

It is important to understand what we already know about the influences on decisions about how children travel to and from school because they inform programs that promote walking and bicycling to school. This section briefly reviews the current literature on this topic that relates to travel choice for school trips. Conceptual models of influences on overall physical activity include three primary influences: individual influences, the social environment, and the built environment, which often interact and overlap (Transportation Research Board, 2005). Individual influences include factors such as demographics, household and lifestyle characteristics, preferences, culture and time allocation. The social environment refers to an array of elements, such as societal values and preferences, public policies and economic or market forces. The built environment comprises the physical setting in communities, and is generally further divided into three categories: land use patterns, transportation systems, and urban design features (Frank, Engelke, \& Schmid, 2003).

While this model was developed primarily to explain influences on overall adult physical activity, the elements provide a useful starting point to begin a discussion about journey-toschool transportation decisions and the effectiveness of programs that promote nonmotorized travel to and from school.

Influences on travel to school decisions and programs that promote healthy transportation for children appear to correspond to the conceptual models of influences on physical activity described above. Many of the studies focus on determining which elements of the built environment, especially those within the right-of-way, are associated with either promoting or discouraging active transportation to and from school. The engineering components of Safe Routes to Schools programs are designed to change some aspect of the built environment near or on the route to school that will promote walking and cycling, usually by improving the safety of the route.

Research is also concerned with personal and social environment influences on mode choice. This includes personal, family and peer attitudes and perceptions that can impact travel choice by and for children, as well as household characteristics that can determine how children travel to school. The education and encouragement elements of Safe Routes programs are usually intended to change one or more aspects of the attitudes or perceptions as a way to effect a behavior change in travel mode.

\section{Personal Influences and the Social Environment}

Studies that examine the personal and social factors that influence decisions on how children travel to school generally focus on the attitudes and perceptions of the parents, household/family characteristics or the social context. Many of these studies take into account the child's age, since it affects what the parents will accept or allow their children to do, especially in terms of safety. For example, (Kerr et al., 2006) found that parents of children aged 12-18 had significant fewer concerns about their children walking or 
biking to school. Fewer of the studies on personal and social influences focus on the child's perceptions and attitudes, especially at the younger ages, since parents are making the travel decisions for them. One study, conducted in 19 Australian primary schools, measured surveyed both parents and children (age 10-12) about their perceptions of the neighborhood relevant to walking and cycling. The researchers found that most children disagreed with their parents' perceptions of heavy traffic and unsafe roads, and that their parents' views of the neighborhood were more negative than their own (A. Timperio, Crawford, D., Telford, A. \& Salmon, J., 2003).

This section outlines the personal and social factors that appear to be most influential on school travel behavior. Some studies have found other interesting influences on travel choice, such as the weight of a child's backpack (Schlossberg, Greene, Phillips, Johnson, \& Parker, 2006), but these findings are not as prevalent in the literature. This may reflect the availability of information in the data sets, such as the national travel survey, used for many these studies, rather than the relative importance of some of these other factors.

\section{Parental Attitudes and Perceptions}

Parental attitudes and perceptions are a major factor in the decisions around children's travel to school (Black, Collins, \& Snell, 2001). Safety is the primary concern of parents who cite worry about both traffic safety and abduction or "stranger danger" (Bradshaw, 1995; Dellinger, 2002); (DiGuiseppi, Roberts, Li, \& Allen, 1998; Johshi, 1995; Joshi, 1995); (McMillan, 2005); (McMillan, 2003); (NHTSA, 2004). In terms of traffic safety, Joshi and Maclean's 1995 study of parent attitudes about their children's school journey found that the child's ability to cross roads was a major concern. Parents also perceive travel distance as a major barrier to walking and cycling to school (Dellinger, 2002; Joshi, 1995; McMillan, 2003; Yarlagadda \& Srinivasan, 2007). Conversely, (Kerr et al., 2006) found that when parents had few concerns, children were five times more likely to actively commute to school, leading to their conclusion that parental education could increase biking and walking to school.

\section{Social Factors}

The social environment and opportunity for interaction is a less prominent but important consideration for some parents when deciding how their children will travel to school (McDonald, 2006) that should be included in a broader definition of the environmental factors affecting these decision (McDonald, 2007c). Children are most likely to walk or bike to school if their parents or caregivers value social interaction for them (McMillan, 2006) or if they live in a neighborhood with other children (A. Timperio et al., 2006). McDonald's 2007 analysis of children's school trip patterns (ages 5-18) in Alameda, California found that social cohesion, as defined by the 2003 California Health Interview Survey, influenced the decision to walk, especially for trips under $1.6 \mathrm{~km}$. The author suggests this indicates that parents are more likely to let children walk when they know and trust their neighbors.

\section{Household Characteristics}

A number of household characteristics also influence how children get to school. For example, Schlossberg et al. (2006) surveyed parents of children at four Oregon middle schools and found that parents have "compelling reasons for driving their children to school that are unrelated to urban form or distance" (Schlossberg et al., 2006), p. 344). This illustrates how a child's travel mode choice is very much a part of the household decision-making process (Black et al., 2001). Household trip interdependencies, especially the linkage between trips to school and work (Black et al., 2001) often play a large role in the decision. For example, Schlossberg et al. (Schlossberg et al., 2006) found that the ease of dropping child off on way to work was cited by $41 \%$ of parents surveyed who drove their kids to school. Earlier work by (Bradshaw, 1995) also found that the possibility of linking the school journey with the trip to work influenced whether children travel to school by car.

Employment and work flexibility of parents are significant determinants of mode choice, but are different for travel to and from school.

(Yarlagadda \& Srinivasan, 2007) found that mothers who worked part-time were more likely to escort their children to school (on foot or bike) compared to both full-time and non-working 
mothers. (McDonald, 2008b) also found evidence that the work status of mothers affects how children get to school. Her research shows that children with mothers who work full time and commute to work in the morning are less likely to walk or bike to school.

Income and family car ownership in the family are two other household factors that are associated with higher rates of being driven (Black et al., 2001); (DiGuiseppi et al., 1998); (Yarlagadda \& Srinivasan, 2007). In addition, walking and cycling to school less likely when household has more licensed drivers to provide rides (McMillan, 2006).

\section{Built Environment}

Planning theories and movements, such as New Urbanism, assume a strong relationship between the built environment and how people move around, often called the land-use transportation connection. These theories posit that making places where destinations are close, the route is interesting, and safety concerns minimized can promote walking and bicycling for both transportation and recreation. A number of studies have found associations between higher levels of walking and shorter travel distances, street connectivity, presence of sidewalks, land use mix, population density, and street design elements. Most of the research to date has focused on adults and trip purposes that do not include travel to school (McMillan, 2005) and may not translate to children nor trip-to-school decisions.

These findings have implications for community planning and design, as well as school trip mode choice. However, Schlossberg et al. (2006) caution that urban form is only one factor in the decision-making process and also that urban form measures seem to be more related to suitability for walking than cycling, suggesting that other influences may be at work on decision to cycle.

There is the added difficulty that some aspects of the built environment can be more easily modified and studied, such as building sidewalks or installing a crossing signal, while others, such as the distance between residences and schools or the connectivity of the street network, are largerscale planning issues that cannot be addressed at the school or neighborhood level. However, some studies have been conducted to evaluate specific aspects of urban form and the findings agree on several elements have an important role in determining whether children are allowed to walk or bike to work.

\section{Distance}

Distance to school is a major deterrent to walking or cycling to school (CDC, 2002), (DiGuiseppi et al., 1998); (Dellinger, 2002); (Ewing, Schroeer, \& Greene, 2004a); (McDonald, 2007a); (Schlossberg et al., 2006); (Yarlagadda \& Srinivasan, 2007).

Children living less than one mile from school are more like to walk or bicycle to (Kweon, Shin, Folzenlogen, \& Kim, 2006); (Dellinger, 2002); (Ewing et al., 2004a); (McMillan, 2003); (Schlossberg et al., 2006); (A. Timperio et al., 2006). These studies also found that the likelihood of active transportation to school decreases as the distance between home and school increases (Yarlagadda \& Srinivasan, 2007).

\section{Street Network \& Connectivity}

The connectivity of the street network also affects the distance and accessibility of schools from residential neighborhoods for walking and bicycling. Two studies found that higher intersection density, or street grids, increased the likelihood of walking to school (Kweon et al., 2006) (Schlossberg et al., 2006). In contrast, (A. Timperio et al., 2006) found that a direct route and inter-connected street network decreased likelihood of active transportation to school, but hypothesized that less-connected streets were less exposed to traffic and therefore viewed by parents as safer for children to walk.

\section{Sidewalks and Street Environment}

The presence of sidewalks, especially on main roads, increases the potential that children will walk to school (Boarnet, Anderson, Day, McMillan, \& Alfonzo, 2005a); (Boarnet, Day, Anderson, McMillan, \& Alfonzo, 2005b); (Kweon et al., 2006). The comfort and attractiveness of the street environment also help promote walking and cycling to school. Kweon et al. (2006) found that landscape buffers and trees add to parents' perceptions of their children's safety and increased their willingness to let their children to walk to school. They also found that children walk more in older neighborhoods with mature trees.

However, they do not address whether older 
neighborhoods serve as a proxy for interconnected street networks and/or distance to school.

\section{Traffic Danger/Safety}

Traffic danger near schools posed by high traffic volumes and erratic driving behavior of parents also impact the way children travel to school (Anderson, Boarnet, McMillan, Alfonzo, \& Day, 2003); (Black et al., 2001); (Bradshaw, 2001); (CDC, 2002); (Dellinger, 2002). For example, $23 \%$ of parents surveyed in a study by

Schlossberg et al. (2006) cited traffic conditions as a reason to drive kids to school. Objective measures of a dangerous environment, such as a busy road barrier, such as a freeway, highway or arterial road) prevents parents from allowing their children to walk or bike to school (A. Timperio et al., 2006). Higher traffic volumes (more than 750 per hour) and speeds (over $40 \mathrm{mph}$ ) increases the risk of crashes near schools and speeds greater than $30 \mathrm{mph}$ along the route decreased the probability that a child would be allowed to bike or walk (Anderson et al., 2003).

\section{Lack of safe crossings}

A lack of lights or crossings reduces the likelihood of walking or cycling to school (A. Timperio et al., 2006). This is further supported by a study by (Boarnet et al., 2005b) which found that replacing four-way stop signs with traffic signals increased the number of children walking in two locations. However, the same study found limited or no evidence of improvement with pedestrian-activated, in pavement flashing warning light systems at crosswalks, a pedestrian-activated "count down" light and a new crosswalk with signs.

\section{Other Environmental Elements}

Since elements of the natural environment cannot be modified or controlled to address barriers to walking and cycling, studies of the influence of these factors on travel to school mode choice are not included in this review. However, in research that has taken a comprehensive look at the factors that influence mode choice, bad weather and steep hills are two elements that are cited as reasons why parents drive their kids to school (Schlossberg et al., 2006); (CDC, 2002).

\section{School Location and Choice Policies}

Programs promoting active transportation to school deal with existing circumstances: where the children live and where the schools are located. They cannot address the factors that affect these variables. However, with the research to date showing that distances is one of the strongest predictors of walking and cycling to work, school policies that promote school choice and set guidelines for school facilities (including size and location) can have a big impact on the distance between home and school, and by association, the mode choice for travel to and from school. The literature on this topic rarely addresses either topic, although a few have turned up some important findings in these areas.

(Bradshaw, 1995) found that parental choice of school was a factor in the decision to drive children to school and that increasingly, parents were not choosing the closest school to home for their children. This trend has serious implications for active transport to school if parents are sending their children to schools that are not located within walking or bicycling distance.

Beaumont (2000) criticizes school siting policies that encourage new school construction in remote areas that are long distances from most students' homes, but does not specifically address the repercussions of these decisions in terms of school journey mode choice. Research has found that children are more likely to walk to bike to small neighborhood schools as opposed to "mega schools in remote areas" (,(Ewing, Schroeer, \& Greene, 2004b), p. 55). . (Braza (2004) also found that walking and biking rates were higher to smaller schools in a study of 34 California public elementary schools. These findings speak to the need for school policy to support smaller neighborhood schools if getting children to walk and bike to school is a priority.

(McDonald, 2008a), finding that walk travel time is the most policy-relevant factor affecting the decision to walk to school, calls for communities to address the spatial distribution of students and schools by coordinating planning school facilities with land use and transportation. She also notes that due to the number of aging schools in the U.S., substantial school renovation and new construction will be taking place. However, when 
testing a community school model that would use distance to school as a criterion for decisions about school facilities, she found that building schools within 1-2 km of students could potentially increase walking and cycling to school, but would only be possible at moderate to higher densities.

\section{PROGRAM EVALUATION FINDINGS}

While the programs to promote active transportation to school have been embraced by schools and government in many communities, few evaluations of the programs appear in the literature. The program evaluations that have been published generally examine the changes in travel behavior before and after programs were implemented, while a few focus on the safety benefits of the engineering improvements that are often a component of Safe Routes to School programs (Dumbaugh \& Frank, 2006). This section summarizes the evaluations and results of such programs that have taken place.

\section{Education and Encouragement Programs}

The initial Marin County Safe Routes to School program, one of the country's first, consisted primarily of education, encouragement and assisting students identify safe walking and cycling routes. Student surveys in the first year of the program (at six school sites) showed that the share of walking increased from $14 \%$ to $22 \%$, biking increased from seven percent to $11 \%$, carpooling increased from $11 \%$ to $18 \%$, and driving along decreased from $62 \%$ to $44 \%$ (Marin County Bicycle Coalition, 2001). Student surveys conducted in all 15 participating schools during the second program year showed a $64 \%$ increase in the number of school trips by walking, a $114 \%$ increase in trips made by bike and a $91 \%$ increase in carpooling trips, while trips by private autos carrying one student decreased by $39 \%$, but mode shares were not reported in the paper (Staunton et al., 2003). While the published evaluation provided a good start in determining the changes in travel mode to and from school, more rigor is needed for a complete evaluation. For example, no control sites were included in the evaluation. In addition, the evaluation did not attempt to correlate specific program activities with behavior change, although analyzing the effectiveness of individual program activities was recommended as a "next step" (Staunton et al., 2003). The evaluation also did not attempt to correlate transportation mode with distance between home and school. Since the literature shows that distance is a strong indicator of mode choice it would be important to know how many students who are being drive to school live more than one mile away, the distance when propensity for active transportation declines.

Few evaluations of walking school buses have been done (Hong, 2007; Kingham \& Ussher, 2006) although they have been a popular method of encouraging more walking to school. The evaluation of a Walking School Bus program in Christchurch, New Zealand measured benefits from the program, but did not include an evaluation of the impact on mode choice. They concluded that the greatest benefit of the program was the social connections built by both children and adults, but also found that it helped change habits so the children preferred to walk (Kingham \& Ussher, 2006).

However, in another study of walking school bus programs in 34 Auckland schools, (Collins D. C. A. \& Kearns, 2005) found an inequitable distribution of the programs within that city, with more programs implemented in affluent neighborhoods. They conclude that the programs there were motivated less by reducing child pedestrian injury and more by an economic and political priority to reduce congestion.

\section{Engineering and Infrastructure Projects}

There is a lack of empirical evidence about the effectiveness of the safety improvements built as part of Safe Routes to Schools programs.

(Dumbaugh \& Frank, 2006) argue for knowledge on the actual effects of these construction projects on child pedestrian safety and claim that "substantive discussions of traffic safety are largely absent from the Safe Routes to School literature." (p. 1). Evaluation of the engineering component of Safe Routes to School programs is critical for two reasons. First, large amounts of funding, especially in states such as California, are being spent on engineering solutions, so it would be logical to study which ones are worth the money and improve child safety. Second, safety is cited by parents as an important determinant of their children's travel mode. Providing conclusive 
evidence that specific improvements make walking and cycling safer is critical to addressing this concern in parents' decisions about how their children get to school.

(Dumbaugh \& Frank, 2006) work provides a point of departure for evaluating infrastructure projects aimed at improving pedestrian and bicycle safety on school routes. They examined the empirical evidence on the countermeasures most commonly employed by Safe Routes to School programs and how those countermeasures affect substantive safety - the actual likelihood of a child being involved in a crash. The engineering countermeasures they examined were: sidewalks, bicycle lanes, speed-reducing traffic calming applications, crosswalks (signalized and unsignalized) and medians and refuge islands. Overall, they found few studies that had evaluated the pedestrian safety effects of these countermeasures, and most of those were not focused specifically on children. Their review concluded that the benefits were largely presumed, and only sidewalks and raised medians were found to reduce pedestrian-vehicle crashes. In addition, none of the studies focused on specific effects on child pedestrians, strengthening their argument for more empirical evidence, especially focusing on child pedestrians.

A study by Boarnet et al. (2005b) begins to address this gap by evaluating Safe Routes to School construction projects designed to improve children's walking bicycling safety to school. They selected ten study school sites and classified the projects into three types: sidewalk improvements, crossing improvements and traffic control. Sidewalk improvements included constructing new sidewalks, filling gaps in the sidewalk network, building a walking path, and installing curbs and curb cuts. Crossing improvements included adding crosswalks, installing in-pavement crosswalk lighting, and installing pedestrianactivated, "count-down" street-crossing signals. Traffic control projects included installing a traffic signal. They collected data by observing traffic flows and pedestrian counts near each project, conducting an urban design audit within a quarter mile of the school, and conducting a survey of parents of third, fourth and fifth grade students. Thus, the study addressed both the perceived safety and substantive safety of the projects - an important difference articulated by (Dumbaugh \& Frank, 2006).

The survey results found that the proportion of children who walked or bicycled more after the project construction was significantly greater among children for whom the project was along their usual route. It also found that large majorities of parents who noticed the construction projects had a favorable opinion of the project and felt that it would increase safety.

The pedestrian counts found increased walking associated with projects that filled gaps in the sidewalk network and replacing four-way stop signs with traffic signals. They found limited or no evidence of success (defined by increased pedestrian counts) associated with pathway and new sidewalk construction, and all crossing improvement projects. The counts on the bicycle path were too low to draw conclusions about the project's success.

\section{Enforcement}

Although enforcement is a component of the Safe Routes to School program that has been implemented in a number of communities, this literature search did not find research or evidence that speaks to the effectiveness of enforcement in reducing vehicle speeds or changing parents' perceptions of traffic safety. Dumbaugh and Frank (2006) reviewed literature associated with enforcement and concluded that enforcement efforts tend to be effective when police are present, but have no long-term effect in modifying behavior.

\section{ANALYSIS AND CONCLUSIONS}

\section{Influences on Children's Travel Mode Choice}

Overall, research on travel behavior choice is still relatively young, although making progress in identifying the elements that are associated with higher levels of walking and cycling by adults for utilitarian travel. Much less research has focused on children's mode choice, but of those examining children's behavior, most focus on travel to school, since it is a universal destination for youth. And there appears to be some consensus on some 
of the primarily influences on travel to school decisions:

- Parents rule: The attitudes and perceptions of the parents are key determinants of how children get to school. Parents are concerned with safety, with traffic safety generally a higher priority than personal safety (stranger danger).

- distance matters -- living closer to school, especially less than one mile, is associated with higher rates of walking and cycling to school.

- Other household considerations count, especially trip interdependencies.

\section{Research Needs on Travel Mode Influences}

More work is still needed to understand more about the influences on parent's decisions about their children's travel and to tease out the multiple elements acting concurrently (A. Timperio et al., 2006). For example, studies should identify and control for as many factors as possible, such as distance to school, age of child, availability of a car, and other conditions, to obtain data on other influences, such as time constraints and tripchaining priorities. Future studies also should examine the inter-relationship between parental perceptions about aspects of the environment (safety, distance, etc), reality, and their decision to let children walk (McDonald, 2006). This could have implications for program design if the results show that parental fears are ungrounded in reality and education could provide reassurance for parents to allow children to walk or bike.

In addition, the influences on the childrens' decisions, especially as they mature and are more independent, should be studied. While they may not always get their way, childrens' opinions can influence their parents' decisions. In addition, more studies that compare parent and child perceptions would provide valuable information to shape program elements aimed at each group.

\section{Programs to Promote Active Transportation to School}

We know more about influences on travel behavior to school than we do about the effectiveness of programs, such as Safe Routes to School, have been instituted in a number of communities in many states across the U.S. to promote walking and cycling to school. For the most part, these programs have focused on engineering solutions, enforcing speed limits and other vehicular codes in school zones, and programs that educate and encourage students and their parents to consider walking and bicycling for at least some trips to and from school. While these programs appear to gaining in popularity and funding, evaluation of results is sparse.

On the program side, the evaluations that have been conducted, such as in Marin County, do not attempt to correlate specific program elements with behavior change. From this, one can only conclude that the all of the efforts, taken together, made a difference. The lack of rigorous evaluation makes it difficult to conclude what aspects of these programs are effective in increasing the number of students who walk or bicycle to school.

Evaluation of engineering and infrastructure improvements associated with Safe Routes to School has focused on the potential for infrastructure improvements to increase walking and cycling by addressing safety concerns, a primary deterrent to walking and cycling cited by parents. However, most of these programs and projects have not considered their actual effects on child safety (Dumbaugh \& Frank, 2006) which needs to be documented to address safety concerns with confidence.

\section{Research Needs on Program Evaluation}

With limited funding to promote active transportation to school, it is important to document the types of projects that have the most proven potential to get results. Specifically, we need to know what works and why - both to increase active transport and improve children's safety using these modes. To date, evaluation of education and encouragement programs does not appear to have progressed beyond documenting travel mode change over time. In some cases, data on travel mode to and from school has not been collected at program outset, but rather retroactively through parent or student surveys.

Research should inform program design and ideally evaluation should be built in to all programs and projects. This will build the knowledge base by recording and disseminating 
information about the effectiveness of program elements. Results of evaluation can provide a base from which to modify existing programs and design new programs to address unmet needs.

However, it is important to note that the parts of the research agenda proposed here may be difficult or infeasible for several reasons. Most of the suggestions for enhanced evaluation require more data, which translates into time and money. This means that funding at the federal level for program evaluation would need to be significantly increased to obtain additional and more detailed data that is already being collected. To isolate the effects of the program elements, schools and communities would need to be willing and able to implement each program element separately. It may not be politically or programmatically feasible to disaggregate the program components in a way that provides the best research setting for evaluation. This could be somewhat overcome by identifying control sites for data collection, realizing that the pairings may not be exactly comparable in terms of student, parent and environmental characteristics.

Following are recommendations for program evaluation that could inform and enhance local programs to encourage walking and bicycling to school:

- Collect data before and after program implementation. While some studies obtain data, such as travel mode, before a program was initiated, many rely on recall during post-program data, which is less reliable.

- Include control sites. Much of the evaluation conducted to date has been only with schools receiving the program intervention. Without control sites, it is difficult to discern if other influences are at work in changing travel mode to and from school.

- Design research that attempts to discern the relative influence of each program element on behavior change. When several components of a Safe Routes to School program are started at the same time, it is difficult to determine which components effected a behavior change and why. Staggering the implementation of program elements is one way to study the effects of each program element independently.

- Travel abilities change as children get older, so it is important to target programs to specific age groups. This requires collecting data by grade level to ascertain the effectiveness of specific programs by age.

- Research methods need to capture information about travel mode correlated with distance of home from school. This will inform program managers if they are able to change behavior in the students living less than one mile from school who could reasonably be expected to walk or bike to school.

- Research needs to separate recording of behavior change, such as increasing levels of walking and bicycling to school, and evaluation of safety improvements which can, in turn, promote more walking and bicycling.

- Since parents' attitudes and perceptions are an important factor in how children travel, it is critical that studies attempt to differentiate parental perceptions and reality. For example, if a parent states that the school is too far for the child to walk, the research design should match parents with addresses and children's ages to determine if their perception of the distance matches the reality, especially related to the age and ability of their child to walk or bike.

- Continue to evaluate and monitor programs as they age. One problem (Kingham \& Ussher, 2005) identified with the evaluation of walking school bus programs in New Zealand is that they often occur soon after a program is in place and do not monitor for the long term. Longitudinal studies are important for two reasons. First, they help programs transition from new programs to ongoing efforts as they become institutionalized. Second, students and conditions change over time. Continual evaluation can provide feedback to help program managers adapt to a changing landscape. 
For the engineering component, we need information on two fronts to inform the types of improvements that should be funded: (1) the type of measures that will increase a parent's perception of safety so they will allow or encourage their child to walk or bike to school; and (2) empirical evidence that demonstrates the effectiveness of specific countermeasures in reducing crashes involving child pedestrians and safety. As (Dumbaugh \& Frank, 2006) argue, many countermeasures are presumed to increase child pedestrian safety, but there is not much literature documenting the safety outcomes of these projects.

\section{Implications for Program Design}

Programs that promote active transportation to school need to be tailored to address specific influences on travel behavior, and designed to evaluate their effectiveness in affecting those influences to change travel behavior to school. In addition, programs need to be informed by and incorporate evaluation into their implementation so funding can be directed to those programs that are proven to be most effective. To accomplish this, stronger working relationships should be forged between the program administrators at the state and local levels, and the scholars who are examining the effectiveness of these programs. In addition, program funding from the federal and state levels should require more rigorous evaluation and provide additional dollars to ensure that this happens.

\section{Implications for Policy and Planning}

As stated earlier, many of the influences on children's travel are beyond the scope of a Safe Routes to School program. These programs can influence some aspects of journey to school mode choice but are not enough to change all the influences on travel behavior.

While public agencies do not have the ability to directly affect household characteristics, such as employment or car ownership, they do have the responsibility for many decisions that affect the environment in which schools are located and children reside. Local governments can enact planning guidelines that affect distance in several ways. They can require inter-connected street networks, sidewalks and other elements that affect distance and route safety. Both local government and schools need to consider policies that affect the spatial distribution of school and residences (McDonald, 2007b) and encourage schools to be placed in neighborhoods within walking distance (McDonald, 2007a), hearkening back to Clarence Perry's Neighborhood Unit concept for community planning. Finally, school choice policies need to consider how they affect distance to school in allowing parents to choose schools not in their neighborhood and therefore outside reasonable distance for active transportation options (Wilson, Wilson, \& Krizek, 2007).

\section{CONCLUSION}

The literature on the influences on a child's mode of travel to school is small but growing. Much less is known about the effectiveness of programs that promote walking and bicycling to school, mostly because there is a lack of research that has evaluated these programs. Safe Routes to School and other programs that promote active transportation need to incorporate rigorous evaluation to determine their effectiveness in achieving their goals and enhancing children's safety en route

\section{REFERENCES}

Anderson, C., Boarnet, M. G., McMillan, T. E., Alfonzo, M., \& Day, K. (2003). Walking and automobile traffic near schools: data to support an evaluation of school pedestrian safety programs. University of California (System). Transportation Center, 22.

Appleyard, B. S. (2003). Planning Safe Routes to School. Planning, 69(5), 34.

Beaumont, C., \& Pianca, E. (2000). Historic neighborhood schools in the age of sprawl: why Johnny can't walk to school. National Trust for Historical Preservation.

Black, C., Collins, A., \& Snell, M. (2001). Encouraging walking: the case of journey-toschool trips in compact urban areas. Urban Studies, 38(7), 1121-1141.

Boarnet, M. G., Anderson, C. L., Day, K., McMillan, T., \& Alfonzo, M. (2005a). Evaluation of the California Safe Routes to School legislation: urban form changes and children's active transportation to school. American Journal of Preventive Medicine, 28, 134140. 
Boarnet, M. G., Day, K., Anderson, C., McMillan, T., \& Alfonzo, M. (2005b). California's Safe Routes to School Program: impacts on walking, bicycling, and pedestrian safety. Journal of the American Planning Association, 71(3), 301-317.

Bradshaw, R. (1995). Why do parents drive their children to school? Traffic Engineering \& Control, 36(1), 16-19.

Bradshaw, R. (2001). School children's travel: the journey to school. Geography.

Braza, M. S., Schoemaker, W. \& Seeley, A. (2004). Neighborhood design and rates of walking and biking to elementary school in 34 California communities. American Journal of Health Promotion, 19(2), 128-136.

CDC. (2002). Barriers to children walking and biking to school - United States, 1999. Morbidity and Mortality Weekly Report, 51(32).

Collins D. C. A. \& Kearns, R. A. (2005). Geographies of inequality: Child pedestrian injury and walking school buses in Auckland, New Zealand. Social Science \& Medicine, 60, 6169.

Cooper, A., Wedderkoff, N., Wang, H., Andersen, L. B., Froberg, K., \& Page, A. (2006). Active travel to school and cardiovascular fitness in Danish children and adolescents. Medicine and Science in Sports and Exercise, 38(10), 1724-1731.

Cooper, A. R., Page, A. S., Foster, L. J., \& Qahwaji, D. (2003). Commuting to school: are children who walk more physically active? American Journal of Preventive Medicine, 25(4), 273-276.

Dellinger, A. M. (2002). Barriers to children walking and biking to school - United States, 1999. JAMA: Journal of the American Medical Association, 288(11), 1343.

DiGuiseppi, C., Roberts, I., Li, L., \& Allen, D. (1998). Determinants of car travel on daily journeys to school: cross sectional survey of primary school children. British Medical Journal, 316 (7142), 1426-1428.

Dumbaugh, E., \& Frank, L. (2006). Traffic safety and Safe Routes to Schools: synthesizing the empirical evidence. Paper presented at the Transportation Research Board - Annual Meeting.

Ewing, R. H., Schroeer, W., \& Greene, W. (2004a). School location \& student travel: analysis of factors affecting mode choice. Transportation research record, 1895, 55-63.
Ewing, R. H., Schroeer, W., \& Greene, W. (2004b). School location and student travel, analysis of factors affecting mode choice. Transportation Research Record: Journal of the Transportation Research Board, 1895, 55-63.

Frank, L. D., Engelke, P. O., \& Schmid, T. (2003). Health and community design: the impact of the built environment on physical activity. Washington D.C.: Island Press.

Hong, S. (2007). Nearly nixed Tour de Georgia pumps up local economy. Bicycle Retailer and Industry News, 16(11), 19-19.

Hubsmith, D. A. (2006). Safe Routes to School in the United States Children, Youth and Environments, 16(1), 169-190.

Hubsmith, D. A. (2007). Safe Routes to School: 2007 State of the States Report: Safe Routes to School National Partnership.

Johshi, M. S. M., M. (1995). Parental attitudes to children's journeys to school. World Transportation Poklicy and Practice, 1(4), 29-36

Joshi, M. S. M., M. (1995). Parental attitudes to children's journeys to school. World Transportation Poklicy and Practice, 1(4), 29-36

Kerr, J., Rosenberg, D., Sallis, J. F., Saelens, B. E., Frank, L. D., \& Conway, T. L. (2006). Active commuting to school: associations with environment and parental concerns. Medicine \& Science in Sports \& Exercise, 38(4), 787-794.

Kingham, S., \& Ussher, S. (2005). Ticket to a sustainable future: an evaluation of the longterm durability of the Walking School Bus programme in Christchurch, New Zealand Transport policy, 12(4), 314-323.

Kingham, S., \& Ussher, S. (2006). An assessment of the benefits of the walking school bus in Christchurch, New Zealand. Transportation Research Part A: Policy \& Practice, 41(6), 502510.

Kweon, B.-S., Shin, W.-H., Folzenlogen, R., \& Kim, J.-H. (2006). Children and transportation: identifying environments that foster walking and biking to school. Texas Transportation Institute, 37.

Marin County Bicycle Coalition. (2001). Safe Routes to School demonstration project final report. Marin.

McDonald, N. C. (2006). Exploratory analysis of children's travel patterns. Transportation Research Record: Journal of the Transportation Research Board, 1977, 1-7. 
McDonald, N. C. (2007a). Active transportation to school: trends among U.S. schoolchildren, 1969-2001. American Journal of Preventive Medicine, 32(6), 509-516.

McDonald, N. C. (2007b). Children's mode choice for the school trip: the role of distance and school location in walking to school. Transportation.

McDonald, N. C. (2007c). Travel and the social environment: Evidence from Alamda County, California. Transportation Research D, 12(1), 53-63.

McDonald, N. C. (2008a). Children's mode choice for the school trip: the role of distance and school location in walking to school. Transportation, 35, 23-35.

McDonald, N. C. (2008b). Household interactions and children's school travel: the effect of parental work patterns on walking and biking to work. Journal of Transport Geography, In press.

McGlynn, T. (2007). A better way to go Public Works, 137(6), 156-158.

McKenzie, T., \& Kahan, D. (2008). Physical activity, public health, and elementary schools. The Elementary School Journal, 108(3), 171-180.

McMillan, T. E. (2003). Walking and urban form: modeling and testing parental decisions about children's travel. University of California, Irvine.

McMillan, T. E. (2005). Urban form and a child's trip to school: the current literature and a framework for future research. Journal of Planning Literature, 19(4), 440-456.

McMillan, T. E. (2006). The relative influence of urban form on a child's travel mode to school. Transportation Research Part A: Policy \& Practice, 41(1), 69-79.

NHTSA. (2004). Safe Routes to School:practice and promise: United States Department of Transportation.

Rosenburg, D. E., Sallis, J. F., Conway, T. L., Cain, K. L., \& McKenzie, T. (2006). Active transportation to school over 2 years in relation to weight status and physical activity. Obesity, 14(10), 1771-1776.

Safe Routes to School National Partnership, \& Hubsmith, D. A. (2007). Safe Routes to School: 2007 State of the States Report: Safe Routes to School National Partnership.
Schlossberg, M. A., Greene, J., Phillips, P. P., Johnson, B., \& Parker, B. (2006). School trips: effects of urban from and distance on travel mode. Journal of Planning Literature, 72(3), 337346.

Staunton, C. E., Hubsmith, D. A., \& Kallins, W. (2003). Promoting safe walking and biking to school: the Marin County success story. American Journal of Public Health, 93(9), 14311434.

Timperio, A., Ball, K., Salmon, J., Roberts, R., Giles-Corti, B., Simmons, B. D., et al. (2006). Personal, family, social, and environmental correlates of active commuting to school. American Journal of Preventive Medicine, 30(1), 4551.

Timperio, A., Crawford, D., Telford, A. \& Salmon, J. (2003). Perceptions about the local neighborhood and walking and cycling among children. Preventive Medicine, 38( 1), 39-47.

Transportation Research Board. (2005). Does the build environment influence physical activity? Examining the evidence. Washington, D.C.: Transportation Research Board Institute of Medicine of the National Academies.

Wilson, E., Wilson, R., \& Krizek, K. J. (2007). A framework and analysis to examine the implications of school choice on travel behavior and environmental emissions. TRB 2007 Annual Meeting - Washington D.C.

Yarlagadda, A. K., \& Srinivasan, S. (2007). Modeling children's school travel mode and parental escort decisions. Transportation, 35(2). 